\title{
Of Hummingbirds and Helicopters: Hovering Costs, Competitive Ability, and Foraging Strategies
}

\author{
Douglas L. Altshuler, ${ }^{1, *}$ F. Gary Stiles, ${ }^{2}$ and Robert Dudley ${ }^{1,3, \dagger}$
}

1. Section of Integrative Biology, University of Texas, Austin, Texas 78712;

2. Instituto de Ciencias Naturales, Universidad Nacional de Colombia, Apartado 7495, Bogotá, Colombia, and Academy of Natural Sciences of Philadelphia, Philadelphia, Pennsylvania 19103; 3. Smithsonian Tropical Research Institute, Apartado 2072, Balboa, Republic of Panama

Submitted October 9, 2002; Accepted July 9, 2003;

Electronically published January 28, 2004

Online enhancements: tables.

ABSTRACT: Wing morphology and flight kinematics profoundly influence foraging costs and the overall behavioral ecology of hummingbirds. By analogy with helicopters, previous energetic studies have applied the momentum theory of aircraft propellers to estimate hovering costs from wing disc loading (WDL), a parameter incorporating wingspan (or length) and body mass. Variation in WDL has been used to elucidate differences either among hummingbird species in nectar-foraging strategies (e.g., territoriality, traplining) and dominance relations or among gender-age categories within species. We first demonstrate that WDL, as typically calculated, is an unreliable predictor of hovering (induced power) costs; predictive power is increased when calculations use wing length instead of wingspan and when actual wing stroke amplitudes are incorporated. We next evaluate the hypotheses that foraging strategy and competitive ability are functions of WDL, using our data in combination with those of published sources. Variation in hummingbird behavior cannot be easily classified using WDL and instead is correlated with a diversity of morphological and physiological traits. Evaluating selection pressures on hummingbird wings will require moving beyond wing and body mass measurements to include the assessment of the aerodynamic forces, power requirements, and power reserves of hovering, forward flight, and maneuvering. However, the WDL-

* Corresponding author. Present address: California Institute of Technology, Pasadena, California 91125; e-mail: doug@caltech.edu.

† Present address: Department of Integrative Biology, University of California, Berkeley, California 94720.

Am. Nat. 2004. Vol. 163, pp. 16-25. (C) 2004 by The University of Chicago. 0003-0147/2004/16301-20376\$15.00. All rights reserved. helicopter dynamics model has been instrumental in calling attention to the importance of comparative wing morphology and related aerodynamics for understanding the behavioral ecology of hummingbirds.

Keywords: behavioral ecology, energetics, flight, hovering, hummingbird, wing morphology.

The study of animal flight has rapidly advanced through recent experiments using dynamically scaled robotic models of flying animals (Dickinson and Götz 1993; Ellington et al. 1996; Dickinson et al. 1999) and flow visualization of the fluid movements produced by real animal wings (Willmott et al. 1997; Srygley and Thomas 2002; Spedding et al. 2003). It is now clear that animals employ a diverse suite of aerodynamic mechanisms to generate the forces necessary to stay aloft, and new research is focusing on how flying animals can manipulate the fluid medium and generate forces to perform complex maneuvers (Dudley 2002; Fry et al. 2003). Historically, as the science of animal flight has progressed, theories linking flight performance and animal behavior have followed thereafter. A model taxon for the marriage of aerial animal behavior and aerodynamics has been the hummingbirds, which have easily observable behaviors and the most energetically demanding flight modes of any volant vertebrate. Because presentday aerodynamic theories of animal flight are more realistic than the simpler models previously used to analyze hummingbird behavioral ecology, it is timely to reevaluate hypotheses relating hummingbird flight mechanics to their behavior.

Prior aerodynamic analyses of hummingbird hovering flight relied on principles from aeronautics using force measurements from stationary or revolving wings. WeisFogh $(1972,1973)$ adapted the Rankine-Froude momentum theory of propellers as applied to helicopter rotors to estimate the power requirements of hovering animals including hummingbirds. In essence a quasi-steady approach, this helicopter dynamics model states that the average pressure exerted on the surrounding air by a 
hoverer is proportional to its weight and is inversely proportional to the area over which downward momentum is generated by a geometric actuator disc. In animals, the area of the actuator disc is best defined as the horizontal projection of the area swept out by the wings during the wingbeat; in the theory's simplest form, downward airflow induced by the actuator disc is assumed to be of constant magnitude in time and across the disc area (Ellington 1984a). For animals the size of hummingbirds, much of the aerodynamic cost of hovering is assumed to be associated with this downward momentum flux (the so-called induced power requirement). The helicopter dynamics model has been used to compare induced power requirements in hummingbirds for which body weight and certain features of wing morphology and kinematics are either known or assumed (Feinsinger and Chaplin 1975; Feinsinger and Colwell 1978; Feinsinger et al. 1979).

Because hovering hummingbirds beat their wings nearly horizontally (Stolpe and Zimmer 1939), the area swept out by the wings can be taken to be the actuator disc in question. The ratio of body weight to this area has been termed wing disc loading, hereafter WDL (WeisFogh 1972, 1973). Epting and Casey (1973) introduced WDL to the hummingbird literature and defined the actuator disc area as $\pi(b / 2)^{2}$, where $b$ is the wingspan. This definition explicitly assumes that the wings rotate about a point in the center of the body and that each wing flaps through a stroke amplitude of $180^{\circ}$. A definition of WDL conforming to the above criteria has been repeatedly used as a surrogate measure for induced power requirements in hovering (Epting and Casey 1973; Feinsinger and Chaplin 1975; Feinsinger and Colwell 1978; Feinsinger et al. 1979; Epting 1980; Carpenter et al. $1993 b)$. However, this model contains several uncorroborated assumptions. One potential problem is that wingspan is usually estimated from the regression of Greenewalt (1975) relating this parameter to the chord of the closed (folded) wing $f$ (a standard ornithological measure sometimes called "wing length," available for many species from the literature), rather than actually measuring wingspan directly. This approach eliminates species-, sex-, and age-specific variation due to differences in wing proportions (Stiles 1995). Because the wings rotate about the shoulder joints rather than about a single body midpoint, a true measure of wing length would be a more accurate estimate of disc radius than using wingspan for disc diameter. With respect to wingbeat kinematics, the stroke amplitude is often much less than $180^{\circ}$ (Chai and Dudley 1995; Chai and Millard 1997). Thus the usual calculation of WDL will tend to overestimate the area of the actuator disc and underestimate the true WDL and induced power requirements.
Here we first illustrate how the predictive power of the helicopter model for induced power requirements of hummingbirds is increased as more detailed morphological and kinematic data are incorporated. Values for different methods of calculating WDL are compared to estimates of induced power according to the vortex model of Ellington $(1984 a, 1984 b)$. The morphological quantities required for Ellington's model include body mass, wing length, wing area, distribution of wing area along wing length, and aspect ratio of the wings. Kinematic parameters include stroke amplitude, wingbeat frequency, stroke plane angle, and angular velocity and acceleration of the wing assuming simple harmonic motion. Air density, which varies systematically with elevation, is also an integral physical parameter of the model.

Features of hummingbird behavior that have been investigated using the helicopter model of hovering costs include competitive ability and foraging strategy. With respect to the former, the major hypothesis is that dominant individuals will have higher WDL than subordinates (Feinsinger and Chaplin 1975; Feinsinger and Colwell 1978; Feinsinger et al. 1979). Dominance was proposed to correlate positively with WDL and/or inversely to wing length, under the assumption that maneuverability in general and turning speed and angular acceleration specifically should increase as wing size decreases. To evaluate potential links between WDL and competitive ability, we present the results of field observations on competitive interactions among species of hummingbirds along with analysis of previously published data on hummingbird competitive abilities from other authors.

In addition to defending flower clusters or artificial feeders, hummingbirds also engage in another foraging strategy in which the birds "trapline" along a route of smaller patches of undefended flowers (Colwell 1973; Feinsinger and Chaplin 1975; Feinsinger 1976; Feinsinger and Colwell 1978; Stiles and Wolf 1979; Tiebout 1991; Sazima et al. 1995; Garrison and Gass 1999). Feinsinger and Chaplin (1975) proposed that trapliners would maximize foraging efficiency by having low WDL and concomitantly reduced power requirements (Epting 1980), thus yielding more efficient nectar extraction from flowers while hovering. More territorial species and gender or age subclasses, in contrast, could increase foraging efficiency by defending clumped flowers for their exclusive use, thus avoiding nectar loss to competitors (sensu Gill 1978). Selection for efficient hovering would therefore be relaxed, and these territorial birds might instead be under selective pressure to increase the speed and maneuverability of flight, the better to chase intruders. Hence, higher WDL should characterize territorial hummingbirds relative to trapliners. Here, we reexamine this 
Table 1: Regression coefficients and probability values for regressions between loading values and body mass-specific induced power requirements of three species of hummingbirds

\begin{tabular}{|c|c|c|c|c|c|c|}
\hline \multirow{2}{*}{$\begin{array}{l}\text { Variable } \\
\text { and Sex }\end{array}$} & \multicolumn{2}{|c|}{$\begin{array}{l}\text { Selasphorus } \\
\text { rufus }\end{array}$} & \multicolumn{2}{|c|}{$\begin{array}{c}\text { Thalurania } \\
\text { furcata }\end{array}$} & \multicolumn{2}{|c|}{$\begin{array}{c}\text { Phaethornis } \\
\text { koepckeae }\end{array}$} \\
\hline & $R^{2}$ & $P$ & $R^{2}$ & $P$ & $R^{2}$ & $P$ \\
\hline \multicolumn{7}{|l|}{$P_{\mathrm{w}}:$} \\
\hline Females & .361 & .0232 & .639 & $.0097^{\star}$ & .387 & .3915 \\
\hline Males & .480 & .0263 & .148 & .2435 & .007 & .8176 \\
\hline \multicolumn{7}{|l|}{$\mathrm{WDL}_{\mathrm{b}}$ : } \\
\hline Females & .242 & .0742 & .855 & $.0004^{*}$ & .058 & .6022 \\
\hline Males & .506 & .0211 & .034 & .5875 & .037 & .5948 \\
\hline \multicolumn{7}{|l|}{$\mathrm{WDL}_{\mathrm{f}}$ : } \\
\hline Females & .353 & .0250 & .819 & $.0004^{*}$ & .039 & .6730 \\
\hline Males & .554 & .0136 & .014 & .7328 & .011 & .7725 \\
\hline \multicolumn{7}{|l|}{$\mathrm{WDL}_{\mathrm{R}}:$} \\
\hline Females & .682 & $.0003^{\star}$ & .940 & $<.0001^{\star}$ & .226 & .2810 \\
\hline Males & .632 & $.0060^{*}$ & .263 & .1068 & .004 & .8648 \\
\hline \multicolumn{7}{|l|}{$\mathrm{WDL}_{\mathrm{A}}$ : } \\
\hline Females & .701 & $.0002^{*}$ & .994 & $<.0001^{\star}$ & .268 & .2343 \\
\hline Males & .762 & $.0010^{*}$ & .935 & $<.0001^{*}$ & .452 & .0331 \\
\hline
\end{tabular}

Note: Significant $\alpha$ levels were determined with sequential Bonferroni correction (Rice 1989). WDL = wing disc loading.

* Significant after Bonferroni correction.

hypothesis using additional published data on foraging behavior of hummingbirds.

\section{Morphology and the Costs of Hovering Induced Power Estimation}

We examined the connection between WDL and the power costs of hovering using 10 male and 14 female rufous hummingbirds (Selasphorus rufus), nine female and 11 male fork-tailed woodnymphs (Thalurania furcata), and seven female and 10 male Koepcke's hermits (Phaethornis koepckeae). These birds were captured using mist nets or feeder traps in Colorado and southeast Peru and were subsequently tested for flight performance. Immediately upon capture, body masses were measured using a digital balance (Acculab PP2060D), and for each bird the folded wing chord and the wingspan were measured to the nearest $0.5 \mathrm{~mm}$. An image of the wing was recorded by holding the left wing of each bird against graph paper and then filming the stationary wing with a handheld video camera (Sony Video 8XR CCD-TRV16). Still images were digitized from video film using Adobe Premiere (version 5.0.1) and were imported into NIH Image (version 1.6.2) for subsequent analysis. Scale within images was set using known linear distances on the filmed graph. Wing length $(R)$ was first measured from the wing outline, and spanwise wing chords were then determined at 1-pixel intervals using the plot profile function of NIH Image. Total wing area $(S$; for both wings) was then calculated as the sum of the areas of each wing strip, defined as the wing chord (in millimeters) multiplied by the width (in millimeters) of each pixel.

Flight trials were carried out in a chamber $(0.45$ $\mathrm{m} \times 0.45 \mathrm{~m} \times 0.9 \mathrm{~m}$ ) large enough to avoid boundary effects. The wingbeat kinematics of hovering birds were filmed using a Sony Video 8 CCD-TR44 focused on a mirror oriented at $45^{\circ}$ above the flight chamber to obtain horizontal projections of wing motions. The camera recorded flight sequences at $60 \mathrm{~Hz}$ with a $1 / 4,000$ shutter speed. Frame-by-frame analysis of video films allowed measurement of the stroke amplitude of the wings and the wingbeat frequency. Wingbeat frequency was calculated using the interaction frequency between the wing stroke cycle and the camera filming rate (Chai and Dudley 1996). Wing stroke amplitude was measured from extreme wing positions within the wingbeat using a protractor held against a flat video screen. Wingbeat kinematics, physical properties of local air, and morphological characteristics of each bird were then used to calculate body mass-specific induced power output (Ellington 1984b; Wells 1993). Further details of these methods for hummingbirds are given by Chai and Dudley (1996).

Load estimates for flying animals consist of ratios of the body weight (body mass $x$ gravity) to the relevant projection of the wings in the horizontal plane. The simplest estimate, wing loading $P_{\mathrm{w}}$, uses the area of both wings $S$ as the denominator and thus assumes nothing about wing movement. We compared values of $P_{\mathrm{w}}$ to four estimates of WDL that vary in how the actuator disc is calculated: $\mathrm{WDL}_{\mathrm{f}}$, using wingspan $b$ from the Greenewalt (1975) regression of this variable on the measured chord of the folded wing $f ; \mathrm{WDL}_{\mathrm{b}}$, using the measured wingspan $b$; and $\mathrm{WDL}_{\mathrm{R}}$, using the measured wing length $R$. In each of these calculations, we assumed stroke amplitude of $180^{\circ}$. Our final estimate, $\mathrm{WDL}_{\mathrm{A}}$, employs a kinematically based version of the actuator disc, defined as the measured stroke amplitude of the wings multiplied by the measured wing length squared (Ellington 1984a). This final derivation represents the actual area swept out by the wings and is thus the most accurate measure of the actuator disc area (Ellington 1984a). The explanatory power of $P_{\mathrm{w}}$ and the different definitions for WDL was assessed using regressions of the induced power costs against the five values of loading.

\section{Predicting Induced Power Requirements from WDL}

For both genders of all three species, the coefficients of determination were maximal with the inclusion of both wing length and wing stroke amplitude in the $\mathrm{WDL}_{\mathrm{A}}$ model (table 1). Relative to $\mathrm{WDL}_{\mathrm{R}}$, the increase in predictive 
power obtained by incorporating stroke amplitude was considerable for males but relatively modest for females. Induced power requirements were significantly correlated with all of the loading models for females of T. furcata and were not significant for any of the models for both genders of $P$. koepckeae. $\mathrm{WDL}_{\mathrm{f}}$ and $\mathrm{WDL}_{\mathrm{b}}$ performed poorly relative to $\mathrm{WDL}_{\mathrm{R}}$ in most cases and to $\mathrm{WDL}_{\mathrm{A}}$ in all cases, indicating that wingspan, however calculated, is inferior to wing length for calculating the actuator disc area and for predicting induced power. Appreciable error is incurred by assuming that the wings rotate about the geometric center of the body rather than about the shoulder joints and by assuming a wing stroke amplitude of $180^{\circ}$. The simplest metric for comparison is the wing loading $P_{\mathrm{w}}$, which makes no assumption concerning the axis of rotation or the stroke amplitude of the wings; its ability to explain variation in induced power costs is comparable to that of $\mathrm{WDL}_{\mathrm{b}}$ and $\mathrm{WDL}_{\mathrm{f}}$.

\section{Competitive Ability}

\section{Assessing Dominance}

Because many hummingbird species hold and defend territories, it is relatively easy to observe competitive encounters between pairs of con- or heterospecifics as birds compete for flower or feeder access. In a typical scenario, one hummingbird will perch while observing a cluster of flowers or a feeder. As invaders attempt to feed from this territory, the holder will chase the intruder away. In a variation on this theme, a vagrant hummingbird may notice another hummingbird feeding from a patch and attempt to chase off the second bird to free up the patch. By observing these and other behaviors, dominant and subordinate individuals can be identified as the chaser and the chased, respectively. Such observations have been used to study interspecific competition and community structure in many hummingbird communities (Feinsinger 1976; DesGranges 1978; Kodric-Brown and Brown 1978; Kuban and Neill 1980; Feinsinger et al. 1985).

Of the species-rich hummingbird communities in the tropics, three have been studied intensively with respect to interspecific competition: the cloudforest of Monteverde in Costa Rica (Feinsinger 1976), the Volcan de Colima in Mexico (DesGranges 1978), and the islands of Trinidad and Tobago (Feinsinger et al. 1985). From observations of numerous chases and other competitive interactions over the course of many months, large records of aggressive interactions with clear winners and losers were assembled and are presented in the form of dominance matrices from which the intensity of reciprocal competitive interactions can be gauged.

We have studied tropical hummingbird communities along an elevational gradient in southeast Peru in the Departments of Cusco and Madre de Dios between December 1998 and October 1999. Nine sites were visited, spanning an elevational range from 400 to $4,300 \mathrm{~m}$. Over the course of the study, we spent $510 \mathrm{~h}$ in formal observations of focal flower patches, with each observation period lasting $1 \mathrm{~h}$. In addition, we recorded the outcomes of aggressive encounters that were casually observed as we were engaged in other field activities. In total, we recorded 469 chases within and among 29 species at seven of the study sites, but most of the chases (401) were between conspecifics (appendix table A1, available in the online edition of the American Naturalist). Of the intraspecific chases, most of these were between individuals of Heliodoxa leadbeateri, and in many cases it was also possible to distinguish males and females of this highly aggressive species.

\section{Does Dominance Correlate with WDL?}

To test the hypothesis that birds with high WDL are competitively dominant to birds with lower WDL, we compared the WDL values of species that consistently either won or lost in pairwise interactions from the studies in Costa Rica, Mexico, and Trinidad and Tobago, as well as from our own study in Peru. We define dominance as success in more than $70 \%$ of pairwise interactions, regardless of the number of interactions for any given pair. Although this criterion treats all pairwise interactions equally, including those in which only one chase was observed, this method does not bias the results with respect to the hypothesis being tested.

Values for $\mathrm{WDL}_{\mathrm{f}}$ for the species from Costa Rica, Mexico, and Trinidad and Tobago were available from the original articles (Feinsinger 1976; DesGranges 1978; Feinsinger et al. 1985). We also collected morphological and kinematic data for the species in our Peruvian study. Hummingbirds were captured in mist nets, measured immediately, filmed in the flight chamber, banded, and then released. The protocols for measuring morphology, filming free flight, and acquiring kinematic data were the same as for hummingbirds in Colorado. Values for $\mathrm{WDL}_{\mathrm{A}}$ as well as the elevational sites at which the species were encountered are given in table 2, available in the online edition of the American Naturalist. These values are species averages including morphological and kinematic data for what in some species is a broad elevational range. Elevation-specific values for $\mathrm{WDL}_{\mathrm{A}}$ are available upon request.

The WDL values for interspecific species pairs in which one of the species consistently won are plotted in figure 1. If the hypothesis that competitively dominant birds had higher WDL than subordinate birds were supported, then the points in the graphs would tend to fall in the shaded triangle. No such pattern was detected for any of the com- 

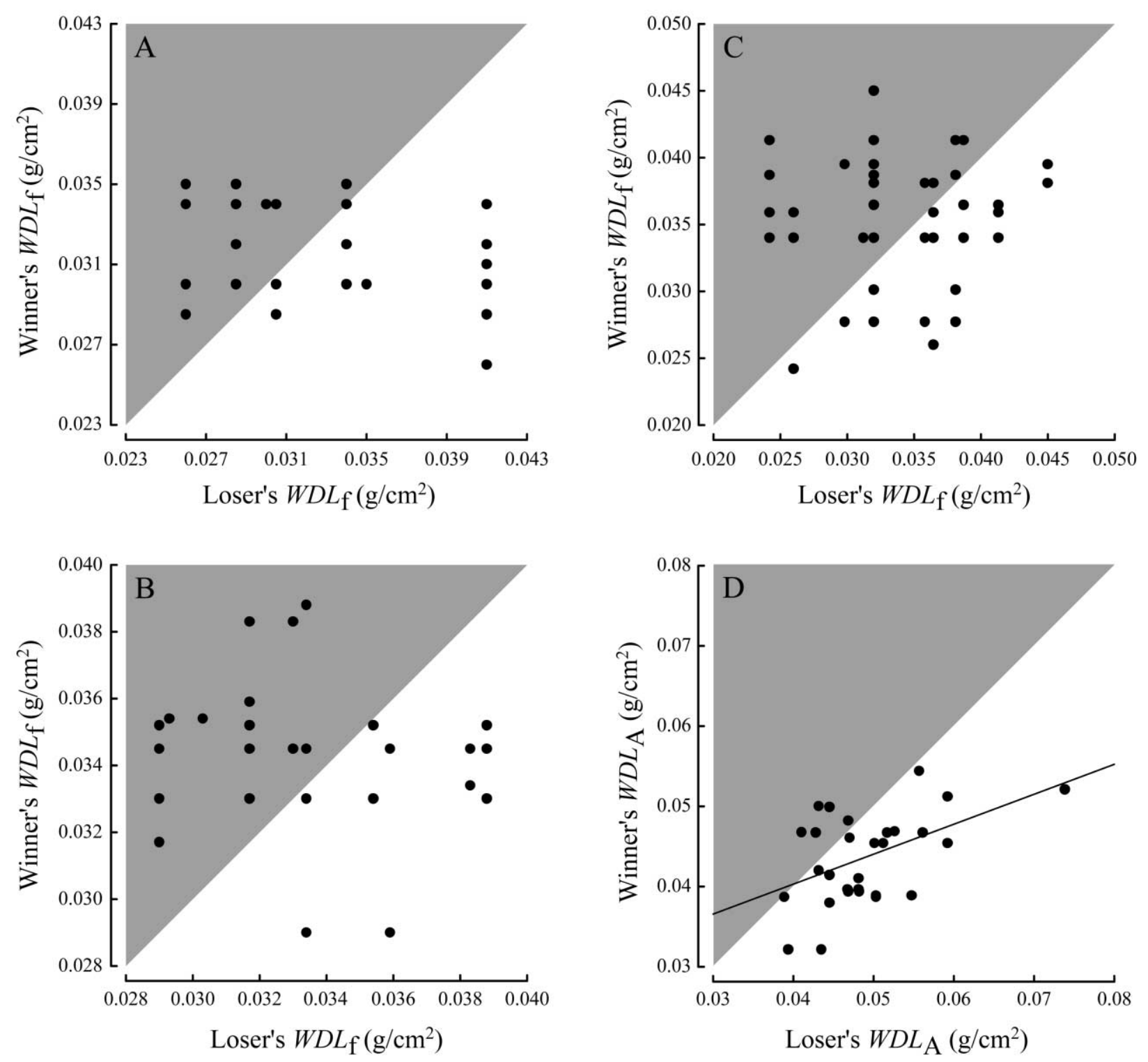

Figure 1: Wing disc loading (WDL) values for species pairwise interactions in which one species (winner) consistently dominated another species (loser). The hypothesis that dominant species have higher WDL than subordinate species would be supported if all or most of the data fell in the shaded region. This hypothesis was not supported with the data from Costa Rica $(A)$, Trinidad and Tabogo $(B)$, or Mexico $(C)$, in which WDL was calculated from the folded wing chord. The hypothesis was also unsupported when WDL was calculated using measured kinematics and wing length for Peruvian hummingbirds $(D)$.

munities studied thus far. The communities in Monteverde, Costa Rica $\left(y=-0.138 x+0.037, R^{2}=0.097\right.$, $P>.1)$, and Trinidad and Tobago $(y=-0.086 x+0.037$, $R^{2}=0.016, P>.5$ ) actually had a slight tendency for birds with lower $\mathrm{WDL}_{\mathrm{f}}$ to be dominant, but the regression model explained little of the variation observed in competitive dominance. The community in Volcan de Colima, Mexico, exhibited no relationship between $\mathrm{WDL}_{\mathrm{f}}$ of the dominant and subordinate species $\left(y=0.0260 x+0.035, R^{2}=\right.$ $0.001, P>.8)$.

Data for competitive interactions across the elevational gradient in Peru are plotted in figure $1 D$. Values for $\mathrm{WDL}_{\mathrm{A}}$ represent site-specific means for the dominant or subordinate species, and no species pairs were observed to compete at more than one site. Unlike the hummingbird communities studied thus far, these data ex- 


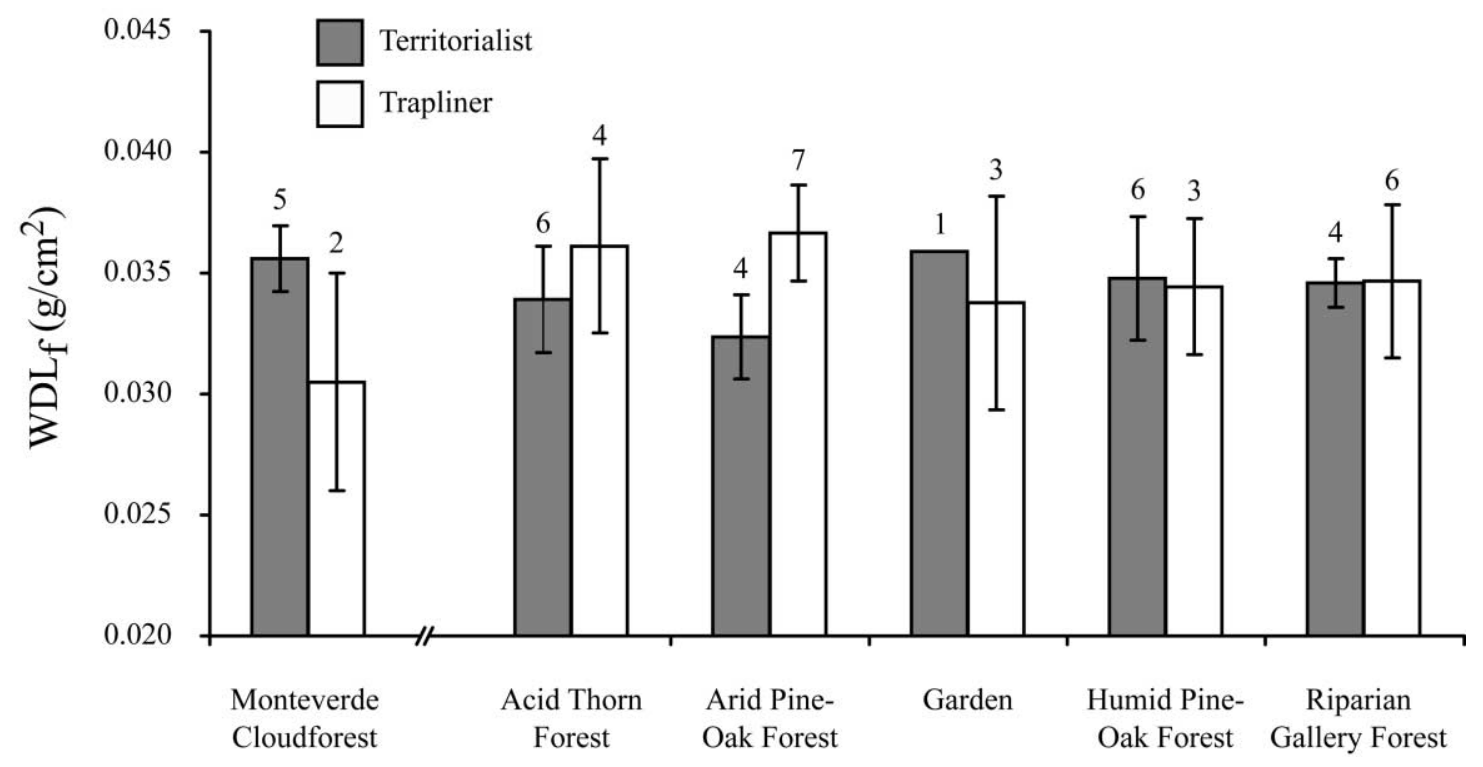

Figure 2: The mean wing disc loading $\left(\mathrm{WDL}_{\mathrm{f}}\right)$ values for territorial and traplining hummingbirds. Bars are standard errors about the mean, and sample sizes are given above.

hibit a significant pattern between WDL and competitive ability $\left(y=-0.374 x+0.025, \quad R^{2}=0.227, \quad P<.01\right)$. However, this is the opposite pattern than predicted because the slope is $<1$ and the majority of the points fall outside the shaded triangle. These results indicate that losers have a consistently higher $\mathrm{WDL}_{\mathrm{A}}$ than the winners. This result is robust and remains significant using each of the formulas for calculating either WDL or wing loading (all $P<.05$ ).

\section{Foraging Strategies}

Besides holding and defending territories, hummingbirds also frequently feed from undefended flowers and "trapline" among dispersed individual flowers or small clusters of them. The major hypothesis is that territorial species have high WDL and traplining species have low WDL, corresponding to high and low power requirements for flight, respectively (Feinsinger and Chaplin 1975). Observations of foraging behavior and classification of hummingbird species into territorial and traplining guilds have been made at the communities of Monteverde in Costa Rica (Feinsinger 1976) and the Volcan de Colima in Mexico (DesGranges 1978).

The foraging behavior of Monteverde hummingbirds has been evaluated in two articles, with slight differences in behavioral classification (Feinsinger 1976; Feinsinger and Colwell 1978). Here we restrict our analysis to the resident Monteverde community for species that are un- equivocally classified as either territorial or traplining in these prior studies. Under such criteria, territorial hummingbirds in the community are made up of males and females of Amazilia saucerottei, Amazilia tzacatl, Hylocharis eliciae, and Philodice bryantae and males of Lampornis calolaema. Traplining hummingbirds include males of Chlorostilbon canivetii and females of Heliomaster constantii. Values for $\mathrm{WDL}_{\mathrm{f}}$ of these hummingbirds at Monteverde are given in Feinsinger and Chaplin (1975). Hummingbirds of the Volcan de Colima community in Mexico were observed over eight months in five habitats (DesGranges 1978). Some taxa that occurred in multiple habitats switched foraging strategies as the species assemblage also varied among habitats. Values for $\mathrm{WDL}_{\mathrm{f}}$ of hummingbirds at the site were also presented by DesGranges (1978).

Mean values of $\mathrm{WDL}_{\mathrm{f}}$ for territorial and traplining hummingbirds at Monteverde and at the five habitats of Volcan de Colima are presented in figure 2. Overall, the $\mathrm{WDL}_{\mathrm{f}}$ values for territorial and traplining hummingbirds are very similar. These data were analyzed with a two-way ANOVA. The two independent variables were foraging behavior (territorial vs. traplining) and site, whereas $\mathrm{WDL}_{\mathrm{f}}$ was the dependent variable. None of the model terms were significant (all $P>.7$ ). Furthermore, the null hypothesis of no difference between values of $\mathrm{WDL}_{\mathrm{f}}$ for hummingbirds employing different foraging strategies was not rejected when the data sets from Costa Rica and Mexico were tested separately (all $P>.15$ ) and when each species was included only once in the analysis $(P>.5)$. 


\section{Discussion}

We have shown that wing disc loading (WDL) is an unreliable predictor of induced power costs but functions best when measured wing lengths and actual stroke amplitudes are used to calculate the area of the actuator disc. Use of wingspan or folded wing chord significantly reduces the predictive power of WDL calculations and weakens conclusions regarding hovering costs. The comparative value of wing disc loading so calculated $\left(\mathrm{WDL}_{\mathrm{f}}\right)$ is further compromised because the relationship between folded wing chord and wing length is not constant across sexage categories either within or among species; wings vary in relative proportions as well as in length (F. G. Stiles, unpublished data). Two major hypotheses relating WDL to hummingbird behavior were tested, and the available data were found to support neither one. No evidence was found to suggest either that high WDL confers a competitive advantage or that territorial hummingbirds have higher WDL than do traplining hummingbirds.

A central tenet of the WDL-helicopter hypothesis it that high WDL increases maneuverability and competitive advantage (Feinsinger and Chaplin 1975; Feinsinger and Colwell 1978; Feinsinger et al. 1979). However, maneuverability refers to diverse aspects of torsional and axial agility. It can be generally defined as the ability to change the speed and direction of movement (Dudley 2002) and sometimes is specifically defined as the minimum turning radius without loss of momentum (Norberg 1994). However, under this more specific definition, maneuverability actually decreases with high wing loading because larger wings are required to generate aerodynamic forces during the slow flight of turns if stalling is to be prevented (Norberg 1994). Similarly, some components of axial agility in vertical load lifting and horizontal forward flight for hummingbirds also increase with decreasing WDL (Chai et al. 1997, 1999), although axial acceleration performance has not been evaluated. Experimental data for torsional agility in hummingbirds is also lacking, but the dependence on WDL is likely to be context specific. For example, acceleration for roll in bats is negatively correlated with wing loading during slow flight speeds but is positively correlated with this parameter during high flight speeds (Norberg 1994). Thus much available data suggest that hummingbird maneuverability is enhanced at lower WDL, but the links between competitive ability and specific aspects of acceleration and torsional agility in particular have not been established.

The best-known and most universal behavioral difference between the genders in hummingbirds is the much stronger territorial behavior of males. Males are more likely to defend rich nectar sources (or feeders) against all other hummingbirds regardless of species or body size, whereas females are more likely to move more widely between poorer sources or to poach nectar furtively from the territories of males (Pitelka 1942; Bené 1946; Stiles 1973; DesGranges 1978; Kodric-Brown and Brown 1978; Carpenter et al. 1993a). Hummingbird competitive behavior has been most intensively studied in the species with breeding ranges north of the border regions between the United States and Mexico. These hummingbirds are from the bee clade (sensu Bleiweiss et al. 1997), which are also among the smallest hummingbirds in the family Trochilidae (Schuchmann 1999). Small hummingbirds are atypical because these birds exhibit reversed sexual dimorphism relative to medium- and larger-sized species. In small hummingbirds, the females are larger than males, whereas males of larger hummingbird species are also typically larger than conspecific females, a pattern known as Rensch's rule (Colwell 2000). For all hummingbird taxa distributed north of the border regions between the United States and Mexico, males are smaller and have higher WDL than females (F. G. Stiles, unpublished data). In addition to lower body mass, higher WDL in males is also unusual in tropical hummingbirds, as suggested by the data of Stiles (1995). Thus, the perception that high WDL confers competitive advantage in hummingbirds may have arisen in part because many published observations refer to species in which males have higher WDL due to phylogenetic associations.

Observations of chases illustrate discrete competitive outcome but alone cannot fully classify dominance status among hummingbirds. Because dominant hummingbirds are attempting to defend either feeding or breeding territories, measurements of success in associated pursuits should also be incorporated. With regard to feeding territories, Pimm et al. (1985) introduced an index of hummingbird competition that measures the ability to dominate a preferred habitat, namely a site with an artificial feeder containing high molarity sucrose. Time spent feeding at the high sucrose feeder is then compared to time spent at a low molarity feeding site, enabling speciesspecific values of dominance to be determined. When studying natural flower visitation, flowering patches of different nectar quantity and quality could be substituted for artificial feeders. Dominance at preferred feeders has been used to detect subtle changes in competitive ability according to variable competitor density and information about habitat types (Mitchell 1989; Sandlin 2000a, 2000b). Use of this or other techniques to discreetly quantify and classify dominance will benefit further study of the link between flight performance and competitive ability.

Similarly for competitive behavior, our analysis of foraging behavior did not reveal a relationship with WDL. However, the distinction between territorial and traplining behavior in hummingbirds is almost certainly an oversim- 
plification of actual foraging options. Feinsinger and Colwell (1978) proposed six community roles based on qualitative observations of nectar foraging behavior from multiple sites, which were found to correlate with differences in body size and $\mathrm{WDL}_{\mathrm{f}}$ as well as with bill length and foot size. In addition, insect foraging behavior has been observed to fall into discrete categories that also correlate with morphology (Stiles 1995). The emerging view is that hummingbirds have a menu of foraging options, and the current challenge is to understand what drives particular choices and how hummingbirds are limited to a subset of these options. The quantitative approach to studying hummingbird competitive ability has proven powerful and is likely to also clarify the influence of flight performance on foraging behavior.

Finally, we wish to emphasize that future attempts to link hummingbird behavior with flight performance would benefit from examining these traits in the context of phylogeny. It is now recognized that species cannot be treated as independent and that trait values must be weighted relative to phylogenetic relationship (Felsenstein 1985). A robust molecular phylogeny of the major lineages of hummingbirds is now available (sensu Bleiweiss et al. 1997) along with lower-level coverage within some of the major clades (Gerwin and Zink 1989; Gill and Gerwin 1989; Roy et al. 1997; García-Moreno et al. 1999), and larger analyses should appear shortly.

\section{Conclusions}

Despite the obviously close relationship between power requirements and the body weight and wing area of hummingbirds, estimations of WDL do not clearly predict hummingbird hovering costs. Flapping hummingbird wings are more complex and variable than helicopter rotors, and the sole wing metric entering into calculation of WDL (wing length or span) is but one of many parameters that will have to be considered before deeper understanding of hummingbird flight is possible (Altshuler and Dudley 2002). Flapping wings in general cannot be modeled as actuator discs imparting a constant downward pressure impulse but rather are oscillating structures that generate complex vortices and time-dependent fluid flows (van den Berg and Ellington 1997a, 1997b; Dickinson et al. 1999; Sane and Dickinson 2001, 2002; Spedding et al. 2003). In retrospect, the main contribution of the helicopter-WDL model has been to call attention to the importance of wing morphology and kinematics in understanding hummingbird flight and behavior. Further progress will come from in-depth study of the power requirements and aerodynamic mechanisms used by hummingbird for hovering, forward flight, and maneuvering, in combination with quantitative measures of foraging and competitive behavior.

\section{Acknowledgments}

We thank an anonymous reviewer for comments on the manuscript. For assistance with fieldwork in Colorado, we thank the Colorado Springs School, P. Baik, C. Evans, A. Gilbert, B. Holmes-Stanciu, O. Starry, and D. Stephens. For assistance with fieldwork in Peru, we thank C. Barber, R. Gibbons, W. Palomino, M. Van Vlaardingen, and R. Yabar. We also gratefully acknowledge the Earthwatch volunteers who made the trip to Peru at their own expense to assist with our research. Funding was provided by grants from the National Science Foundation (IBN-9601089, IBN-9817138, IBN-992155), the Earthwatch Institute, Sigma $\mathrm{Xi}$, and the University of Texas at Austin.

\section{Literature Cited}

Altshuler, D. L., and R. Dudley. 2002. The ecological and evolutionary interface of hummingbird flight physiology. Journal of Experimental Biology 205:2325-2336.

Bené, F. 1946. The feeding and related behaviors of hummingbirds, with special reference to the black-chin, $A r-$ chilochus alexandri. Memoirs of the Boston Society of Natural History 9:403-481.

Bleiweiss, R., J. A. W. Kirsch, and J. C. Matheus. 1997. DNA hybridization evidence for the principal lineages of hummingbirds (Aves: Tochilidae). Molecular Biology and Evolution 4:325-343.

Carpenter, F. L., M. A. Hixon, E. J. Temeles, R. W. Russell, and D. C. Paton. 1993a. Exploitative compensation by subordinate age-sex classes of migrant rufous hummingbirds. Behavioral Ecology and Sociobiology 33: 305-312.

Carpenter, F. L., M. A. Hixon, R. W. Russell, D. C. Paton, and E. J. Temeles. 1993b. Interference asymmetries among age-sex classes of rufous hummingbirds during migratory stopovers. Behavioral Ecology and Sociobiology 33:297-304.

Chai, P., and R. Dudley. 1995. Limits to vertebrate locomotor energetics suggested by hummingbirds hovering in heliox. Nature 377:722-725.

. 1996. Limits to flight energetics of hummingbirds hovering in hypodense and hypoxic gas mixtures. Journal of Experimental Biology 199:2285-2295.

Chai, P., and D. Millard. 1997. Flight and size constraints: hovering performance of large hummingbirds under maximal loading. Journal of Experimental Biology 200: 2757-2763.

Chai, P., J. S. C. Chen, and R. Dudley. 1997. Transient hovering performance of hummingbirds under condi- 
tions of maximal loading. Journal of Experimental Biology 200:921-929.

Chai, P., D. L. Altshuler, D. B. Stephens, and M. E. Dillon. 1999. Maximal horizontal flight performance of hummingbirds: effects of body mass and molt. Physiological and Biochemical Zoology 72:145-155.

Colwell, R. K. 1973. Competition and coexistence in a simple tropical community. American Naturalist 107: 737-760.

- 2000. Rensch's rule crosses the line: convergent allometry of sexual size dimorphism in hummingbirds and flower mites. American Naturalist 156:495-510.

DesGranges, J.-L. 1978. Organization of a tropical nectar feeding bird guild in a variable environment. Living Bird 17:199-236.

Dickinson, M. H., and K. G. Götz. 1993. Unsteady aerodynamic performance of model wings at low Reynolds numbers. Journal of Experimental Biology 174:45-64.

Dickinson, M. H., F.-O. Lehmann, and S. P. Sane. 1999. Wing rotation and the aerodynamic basis of insect flight. Science 284:1954-1960.

Dudley, R. 2002. Mechanisms and implications of animal flight maneuverability. Integrative and Comparative Biology 42:135-140.

Ellington, C. P. 1984a. The aerodynamics of hovering insect flight. V. A vortex theory. Philosophical Transactions of the Royal Society of London B 305:115-144.

- 1984b. The aerodynamics of hovering insect flight. VI. Lift and power requirements. Philosophical Transactions of the Royal Society of London B 305:145-181. Ellington, C. P., C. van den Berg, A. P. Willmott, and A. L. R. Thomas. 1996. Leading-edge vortices in insect flight. Nature 384:626-630.

Epting, R. J. 1980. Functional dependence on the power for hovering on wing disc loading in hummingbirds. Physiological Zoology 53:347-357.

Epting, R. J., and T. M. Casey. 1973. Power output and wing disc loading in hovering hummingbirds. American Naturalist 107:761-765.

Feinsinger, P. 1976. Organization of a tropical guild of nectarivorous birds. Ecological Monographs 46:257291.

Feinsinger, P., and S. B. Chaplin. 1975. On the relationship between wing disc loading and foraging strategy in hummingbirds. American Naturalist 109:217-224.

Feinsinger, P., and R. K. Colwell. 1978. Community organization among Neotropical nectar-feeding birds. American Zoologist 18:779-795.

Feinsinger, P., R. K. Colwell, J. Terborgh, and S. B. Chaplin. 1979. Elevation and the morphology, flight energetics, and foraging ecology of tropical hummingbirds. American Naturalist 113:481-497.

Feinsinger, P., L. A. Swarm, and J. A. Wolfe. 1985. Nectar- feeding birds on Trinidad and Tobago: comparison of diverse and depauperate guilds. Ecological Monographs 55:1-28.

Felsenstein, J. 1985. Phylogenies and the comparative method. American Naturalist 125:1-15.

Fry, S. N., R. Sayaman, and M. H. Dickinson. 2003. The aerodynamics of free-flight maneuvers in Drosophila. Science 300:495-498.

García-Moreno, J., P. Arctander, and J. Fjeldså. 1999. Strong diversification at the treeline among Metallura hummingbirds. Auk 116:702-711.

Garrison, J. S. E., and C. L. Gass. 1999. Response of a traplining hummingbird to changes in nectar availability. Behavioral Ecology 10:714-725.

Gerwin, J. A., and R. M. Zink. 1989. Phylogenetic patterns in the genus Heliodoxa (Aves, Trochilidae): an allozymic perspective. Wilson Bulletin 101:525-544.

Gill, F. B. 1978. Proximate costs of competition for nectar. American Zoologist 18:753-763.

Gill, F. B., and J. A. Gerwin. 1989. Protein relationships among hermit hummingbirds. Proceedings of the Academy of Natural Sciences of Philadelphia 95:412-420.

Greenewalt, C. H. 1975. The flight of birds. Transactions of the American Philosophical Society 65:1-67.

Kodric-Brown, A., and J. H. Brown. 1978. Influence of economics, interspecific competition, and sexual dimorphism on territoriality of migrant rufous hummingbirds. Ecology 59:285-296.

Kuban, J. F., and R. L. Neill. 1980. Feeding ecology of hummingbirds in the highlands of the Chisos mountains, Texas. Condor 82:180-185.

Mitchell, W. A. 1989. Informational constraints on optimally foraging hummingbirds. Oikos 55:145-154.

Norberg, U. M. 1994. Wing design, flight performance, and habitat use in bats. Pages 205-239 in P. C. Wainwright and S. M. Reilly, eds. Ecological morphology. University of Chicago Press, Chicago.

Pimm, S. L., M. L. Rosenzweig, and W. Mitchell. 1985. Competition and food selection: field tests of a theory. Ecology 66:798-807.

Pitelka, F. A. 1942. Territoriality and related problems in North American hummingbirds. Condor 44:189-204.

Rice, W. R. 1989. Analyzing tables of statistical tests. Evolution 43:223-225.

Roy, M. S., J. C. Torres-Mura, and F. Hertel. 1997. Evolution and history of hummingbirds (Aves: Trochilidae) from the Juan Fernandez Islands, Chile. Ibis 140:265273.

Sandlin, E. A. 2000a. Cue use affects resource subdivision among three coexisting hummingbird species. Behavioral Ecology 11:550-559.

- 2000b. Foraging information affects the nature of competitive interactions. Oikos 91:18-28. 
Sane, S. P., and M. H. Dickinson. 2001. The control of flight force by a flapping wing: lift and drag production. Journal of Experimental Biology 204:2607-2626. . 2002. The aerodynamic effects of wing rotation and a revised quasi-steady model of flapping flight. Journal of Experimental Biology 205:1087-1096.

Sazima, I., S. Buzato, and M. Sazima. 1995. The saw-billed hermit Ramphodon naevius and its flowers in southeastern Brazil. Journal für Ornithologie 136:195-206.

Schuchmann, K. L. 1999. Family Trochilidae (hummingbirds). Pages 468-680 in J. del Hoyo, A. Elliott, and J. Sargatal, eds. Handbook to the birds of the world. Lynx Edicions, Barcelona.

Spedding, G. R., M. Rosén, and A. Hedenström. 2003. A family of vortex wakes generated by a thrush nightingale in free flight in a wind tunnel over its entire natural range of flight speeds. Journal of Experimental Biology 206:2313-2344.

Srygley, R. B., and A. L. R. Thomas. 2002. Unconventional lift-generating mechanisms in free-flying butterflies. $\mathrm{Na}$ ture 420:660-664.

Stiles, F. G. 1973. Food supply and the annual cycle of the Anna hummingbird. University of California Publications in Zoology 97:1-108.

- 1995. Behavioral, ecological and morphological correlates of foraging for arthropods by the hummingbirds of a tropical wet forest. Condor 97:853-878.

Stiles, F. G., and L. L. Wolf. 1979. Ecology and evolution of lek mating behavior in the long-tailed hermit hum- mingbird. Ornithological monographs. Vol. 27. American Ornithologists' Union, Washington, D.C.

Stolpe, V. M., and K. Zimmer. 1939. Der Schwirrflug des Kolibri im Zeitlupenfilm. Journal für Ornithologie 87: 136-155.

Tiebout, H. M. 1991. Daytime energy management by tropical hummingbirds: responses to foraging constraint. Ecology 72:839-851.

van den Berg, C., and C. P. Ellington. 1997a. The threedimensional leading-edge vortex of a "hovering" model hawkmoth. Philosophical Transactions of the Royal Society of London B 352:329-340.

- 1997b. The vortex wake of a "hovering" model hawkmoth. Philosophical Transactions of the Royal Society of London B 352:317-328.

Weis-Fogh, T. 1972. Energetics of hovering flight in hummingbirds and in Drosophila. Journal of Experimental Biology 56:79-104.

—. 1973. Quick estimates of flight fitness in hovering animals, including novel mechanisms for lift production. Journal of Experimental Biology 59:169-230.

Wells, D. J. 1993. Muscle performance in hovering hummingbirds. Journal of Experimental Biology 178:39-57.

Willmott, A. P., C. P. Ellington, and A. L. R. Thomas. 1997. Flow visualization and unsteady aerodynamics in the flight of the hawkmoth, Manduca sexta. Philosophical Transactions of the Royal Society of London B 352:303316.

Associate Editor: Peter C. Wainwright 